\title{
Compatibility of conventional agrochemicals used in rice crops with the entomopathogenic fungus Metarhizium anisopliae
}

\author{
Rodrigo Alves da Silva ${ }^{1,2}$, Eliane Dias Quintela ${ }^{1}$, Gabriel Moura Mascarin ${ }^{1 *}$, José Alexandre Freitas Barrigossi ${ }^{1}$, Luciano Moraes \\ Lião²
}

'Embrapa Arroz e Feijão, Rod. G0-462, km 12, Zona Rural, C.P. 179 - 75375-000 - Santo Antônio de Goiás, GO Brasil.

2Universidade Federal de Goiás/Instituto de Química, Campus Samambaia, C.P. 131 - 74001-970 - Goiânia, G0 - Brasil.

*Corresponding author <gabriel.mascarin@embrapa.br>

Edited by: Richard V. Glatz
ABSTRACT: The toxicological impact of chemical pesticides on fungal entomopathogens and their use in tank-mixing can be directly measured through in vitro compatibility tests. This study reports the in vitro toxicity of eight insecticides, four fungicides and five herbicides in the conidial germination, vegetative growth and conidiation of Metarhizium anisopliae (strain CG 168). A conidial suspension containing the pesticide at recommended field dosage was subjected to constant agitation in a rotary shaker for 3 h to simulate a tank mixing. Then, aliquots of each suspension were used to determine conidial germination, vegetative growth and conidiation on potato dextrose agar (PDA). The fungicides difenoconazole $\left(69 \mathrm{~mL} \mathrm{ha}^{-1}\right.$ ), propiconazole (75 mL ha-1), trifloxystrobin (313 $\mathrm{g} \mathrm{ha}^{-1}$ ) and azoxystrobin (56 $\mathrm{mL} \mathrm{ha}^{-1}$ ) were the most harmful products to all biological stages of $M$. anisopliae and they should not be applied together with this fungus in tank mixing. The insecticides exhibited the least degree of toxicity to this fungal pathogen, whereas the herbicides had the greatest impact on mycelial growth. The agrochemicals compatible with $M$. anisopliae were the insecticides methyl parathion (240 $\mathrm{mL} \mathrm{ha}^{-1}$ ), thiamethoxam (31 $\mathrm{g} \mathrm{ha}^{-1}$ ), and lambda-cyhalothrin (6.3 $\mathrm{mL} \mathrm{ha}^{-1}$ ) and the herbicides glyphosate (1560 mL ha-1), bentazon (720 $\left.\mathrm{mL} \mathrm{ha}^{-1}\right)$, and imazapic + imazapyr (84 $\left.\mathrm{g} \mathrm{ha}^{-1}\right)$. The compatible pesticides could be simultaneously used with this bio-control agent for integrated pest management in rice production systems.

Keywords: pesticide compatibility, conidiation, entomopathogenic fungi, germination, vegetative growth
Biocontrol agents, such as entomopathogens, cannot totally replace synthetic chemical pesticides in commercial rice production systems. As there is strong evidence indicating the harmful effects of them on the survival of entomopathogenic fungi in the agroecosystem, it is crucial to determine the compatibility of such agrochemicals and to determine which of them are less harmful to $M$. anisopliae in order to guide rice growers. In addition, the combination approach among control measures, such as microbial agents and chemical insecticides, comprises an important component in integrated pest management programs (Quintela and McCoy, 1997). Toxicity of such pesticides to fungal entomopathogens may vary with fungus species and strain, chemical nature of the active ingredient, mode of action, product formulation, and recommended label rate (Alves and Lecuona, 1998). For instance, Tanzini et al. (2002) observed that two different strains of $M$. anisopliae showed different responses when exposed to methamidophos and lambda-cyhalothrin. Therefore, the objective of this study was to determine the compatibility of different agrochemicals registered for rice crops with a selected isolate of $M$. anisopliae under laboratory conditions.

\section{Materials and Methods} of widely used agricultural chemicals on $M$. anisopliae is variable, with fungicides generally being the most toxic compounds followed by insecticides and herbicides (Loureiro et al., 2002; Rachappa et al., 2007; RampelottiFerreira et al., 2010; Tanzini et al., 2002).

\section{Source of fungus inoculum}

Bioassays were carried out in Santo Antônio de Goiás (16 $28^{\prime} 00^{\prime \prime}$ S, 49 $17^{\prime} 00^{\prime \prime} \mathrm{W}$ and $823 \mathrm{~m}$ a.s.1.), State 
of Goiás, Brazil. M. anisopliae was isolated from T. limbativentris adult at Santo Antônio de Goiás, GO, in 1985. This strain was identified as being $M$. anisopliae through the sequence analysis of elongation factor 1-alpha gene, following the protocol described in Bischoff et al. (2009). In 1990, this $M$. anisopliae strain was stored at the culture collection of Embrapa Genetic Resources and Biotechnology (Cenargen), in Brasília, Federal District, Brazil, and is currently identified as M. anisopliae strain CG 168.

\section{Agrochemicals tested}

The insecticides, fungicides and herbicides chosen for the bioassays are the most frequently used by rice farmers and described in Table 1. These pesticides are registered for use in rice crops in Brazil. The concentrations of all agrochemicals were tested following the label rates recommended by the manufacturers (MAPA, 2009). When the concentration of a product indicated minimum and maximum doses, the average concentration was used. Methamidophos is a known broad spectrum insecticide not yet registered for rice, though it is widely used by farmers to control T. limbativentris (J.A.F. Barrigossi, personal communication, Jul. 31, 2011). The concentration tested for each product was calculated based on the spray volume rate of $200 \mathrm{~L} \mathrm{ha}^{-1}$ of water.

\section{Conidial germination, mycelial growth and conidial production bioassays}

A new procedure is described herein simulating a tank mixing with the chemical products and the fungus before application. Three most important biological parameters of the fungus were recorded: conidial germination, vegetative growth and conidiation.

In the first experiment, the effect of eight insecticides was assessed on fungal germination rate. Each insecticide concentration was added to $10 \mathrm{~mL}$ of fungal suspension containing $1.9 \times 10^{7}$ conidia $\mathrm{mL}^{-1}$ in sterile distilled water plus Tween 80 (polyoxyethylene (80) sorbitan monooleate, Vetec Química Fina Ltda., Rio de Janeiro, RJ, Brazil) at $0.01 \%(\mathrm{v} / \mathrm{v})$ using $50-\mathrm{mL}$ centrifuge tubes. Each treatment (i.e., mixture of fungal conidia + pesticide) was replicated four times (i.e., four tubes per treatment). Then, this mixture was vigorously vortexed for $2 \mathrm{~min}$ and kept at constant agitation in a rotary shaker at $25{ }^{\circ} \mathrm{C}$ with 214 revolutions per minute for 3 $\mathrm{h}$ in order to simulate a tank mixing of fungal conidia and pesticide. The suspension was vortexed again and a $500-\mu \mathrm{L}$ aliquot was sprayed onto a thin layer $(3 \mathrm{~mm})$ of PDA (20\% potato infusion, $2 \%$ dextrose and $2 \%$ agar) on a glass slide $(7.5 \times 2.5 \mathrm{~cm})$ using a hand sprayer. Each treatment had three slides (replicates). After conidial inoculation, these slides were placed in a growth chambers at $26 \pm 1{ }^{\circ} \mathrm{C}$, relative humidity $(\mathrm{RH})$ of $70 \pm 8 \%$ with $12 \mathrm{~h}$ photophase. Control consisted of conidia suspended only in $0.01 \%$ aqueous Tween 80 free of any chemical pesticide. Conidial germination was determined after 20 and $48 \mathrm{~h}$ of incubation period by examining 200 conidia at random per slide, using a phase-contrast microscope

Table 1 - Description of agrochemicals used in rice production for assessment of in vitro compatibility bioassays with Metarhizium anisopliae CG 168 .

\begin{tabular}{|c|c|c|c|c|c|}
\hline Trade name & Formulation ${ }^{\mathrm{a}}$ & Chemical group & Technical name & $\begin{array}{l}\text { Concentration of } \\
\text { active ingredient }\end{array}$ & $\begin{array}{l}\text { Recommended } \\
\text { dose }\end{array}$ \\
\hline & & & & $\mathrm{g} \mathrm{L}^{-1}$ or $\mathrm{g} \mathrm{kg}^{-1} \mathrm{~b}$ & g or mL ha-1 \\
\hline \multicolumn{6}{|l|}{ Insecticide } \\
\hline Standak & SC & Pyrazole & Fipronil & 250 & 240 \\
\hline Bravik & EC & Organophosphate & Methyl Parathion & 600 & 400 \\
\hline Nor-trin & $\mathrm{EC}$ & Pyrethroid & Cypermethrin & 250 & 100 \\
\hline Actara & WG & Neonicotinoid & Thiamethoxam & 250 & 125 \\
\hline Engeo Pleno & CS & Neonicotinoid + Pyrethroid & Thiamethoxam + Lambda-cyhalothrin & $106+141$ & 175 \\
\hline Karate Zeon & CS & Pyrethroid & Lambda-cyhalothrin & 50 & 125 \\
\hline Klap & CS & Pyrazole & Fipronil & 200 & 60 \\
\hline Tamaron & CS & Organophosphate & Methamidophos & 600 & 100 \\
\hline \multicolumn{6}{|l|}{ Herbicide } \\
\hline Roundup Original & CS & Glycine replaced & Glyphosate & 480 & 3250 \\
\hline DMA & SL & Ariloxialconoic acid & 2,4-Dichlorophenoxyacetic acid (2,4-D) & 806 & 1000 \\
\hline Basagran & SL & Benzothiadiazinone & Bentazon & 600 & 1200 \\
\hline Kifix & WP & Imidazolinone & Imazapic + Imazapyr & $175+525$ & 120 \\
\hline Herbadox & $\mathrm{EC}$ & Dinitroanilines & Pendimethalin & 500 & 3000 \\
\hline \multicolumn{6}{|l|}{ Fungicide } \\
\hline Score & $\mathrm{EC}$ & Triazole & Difenoconazole & 250 & 275 \\
\hline Stratego & $\mathrm{EC}$ & Triazole & Propiconazole & 250 & 300 \\
\hline Flint & WG & Strobilurin & Trifloxystrobin & 500 & 625 \\
\hline Priori & CS & Strobilurin & Azoxystrobin & 250 & 225 \\
\hline
\end{tabular}

a Formulation types : capsule suspension (CS), emulsifiable concentrate (EC), suspension concentrate (SC), soluble concentrate (SL), water dispersible granules (WG),

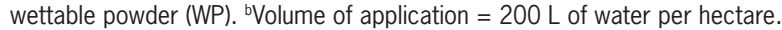


at $400 \times$ magnification. Conidia were considered germinated when the germ tube was longer than the conidial diameter (Luz and Fargues, 1997). This experiment was repeated twice ( $n=6$ replicates).

In the second bioassay, the effect of the insecticides on mycelial growth and conidial production was assessed. Two microliters of each original conidial suspension mixed with pesticide, whose preparation was described in the previous trial, were inoculated in the center of a 6-cm diameter Petri dish containing PDA (10 $\mathrm{mL}$ per plate). Each treatment consisted of four replicates (plates). Control consisted of conidia suspended in $0.01 \%$ aqueous Tween 80 . Plates were then placed in a growth chamber at $26 \pm 1{ }^{\circ} \mathrm{C}, 70 \pm 8 \% \mathrm{RH}$ with $12 \mathrm{~h}$ photophase. After nine days of incubation, the fungal radial growth was determined using a digital caliper rule to record length and width of the fungal colony. Afterwards, the entire colony was cut and transferred to a 50$\mathrm{mL}$ centrifuge tube containing $10 \mathrm{~mL}$ of distilled water + Tween $80(0.01 \%)$ and vigorously vortexed for two minutes, so that conidia were dislodged from the PDA medium. Successive dilutions were performed until a desirable suspension was obtained for counting conidia using an improved Neubauer chamber $1400 \times$ magnification). The conidial production was recorded and expressed as number of conidia per colony. This experiment was repeated twice ( $n=8$ replicates).

The compatibility of five herbicides and four fungicides (Table 1) with $M$. anisopliae strain GC 168 was also evaluated by performing the same bioassay procedures as outlined above for the insecticides. The experiments with the herbicides and fungicides were repeated twice.

\section{Data analysis}

The data sets for each experiment in duplicate were joined for statistical analyses. Residuals derived from data sets were submitted to Shapiro-Wilk and Brown-Forsythe tests of significance at $5 \%$ to check the normality assumptions of the parametric statistical model. For those that matched normality assumptions, data were submitted to a one-way analysis of variance (ANOVA, PROC GLM), and treatment means were post-hoc compared by Fisher's least significant difference (LSD, $\alpha=0.05)$. When residues did not match parametric assumptions, data were submitted to nonparametric analysis based on Kruskal-Wallis test with rank-transformed data (PROC NPAR1WAY), except data of percentage of conidial germination that were previously subjected to arcsin square root transformation. Afterwards, rank means were compared by Fisher's $\operatorname{LSD}(\alpha=0.05)$.

To determine which group of chemical (insecticides, fungicides and herbicides) was more detrimental to each developmental stage of $M$. anisopliae, means within each chemical group were pooled and submitted to the Kruskal-Wallis test, then pooled means were compared by Fisher's LSD test $(\alpha=0.05)$. All statistical analyses were run using SAS software version 9.2 (SAS Institute, 2008).
To determine the selectivity of agrochemicals to entomopathogenic fungi under laboratory conditions, the Biological Index formula $(B I)$ proposed by RossiZalaf et al. (2008) was used, calculated as the following: $B I=\left[47^{*} V G+43^{*} S P+10^{*} G E R\right] / 100$, where: $V G$ is the percentage of vegetative growth of fungal colony in relation to control; SP is the percentage of colony sporulation in relation to control; GER is the percentage of conidial germination in relation to control. Values of $B I$ $(\alpha=0.05)$ were clustered into three categories of toxicological classification of agrochemicals to the fungus: 0 to $41=$ Toxic; 42 to $66=$ Moderately toxic; $>66=$ Compatible. Hence, this formula is considered practical to classify chemical pesticides concerning their toxicity to entomopathogenic fungi.

\section{Results}

All insecticides affected conidial germination at $20 \mathrm{~h}$ in contrast to the untreated control $(F=261.98$; $d f=8,45 ; p<0.0001)$. The highest detrimental effect on conidial germination was caused by fipronil $(25 \%$ w/v) and cypermethrin (reduction of $54 \%$ and $100 \%$, respectively) (Figure 1). At $48 \mathrm{~h}$, thiamethoxam and methyl parathion had not affected conidial germination $\mid p>$ $0.05)$, while the other insecticides reduced germination compared to control $(F=266.7 ; d f=8,45 ; p<0.0001)$. The lowest germination rates were observed for fipronil $(25 \% \mathrm{w} / \mathrm{v})$ and cypermethrin which caused a significant inhibition of conidial germination when compared to thiamethoxam, thiamethoxam + lambda-cyhalothrin, methyl parathion, lambda-cyhalothrin, fipronil $(20 \%$ $\mathrm{w} / \mathrm{v})$ and methamidophos after 20 and $48 \mathrm{~h}$ of incubation $(p<0.05)$.

Mycelial growth was reduced in all insecticide treatments when compared to the untreated control $\left(\chi^{2}\right.$ $=62.14 ; d f=8 ; p<0.0001)$, except methyl parathion which allowed normal fungal growth $(p>0.05)$. No $M$. anisopliae mycelial growth was observed with cypermethrin which was different from the other treatments (Figure 1).

Conidiation of $M$. anisopliae was inhibited by all insecticides $\left(\chi^{2}=63.05 ; d f=8 ; p<0.0001\right)$, except methyl parathion which did not differ from the control $(p>$ 0.05) (Figure 1). Thiamethoxam + lambda-cyhalothrin, fipronil $(20 \% \mathrm{w} / \mathrm{v})$, fipronil $(25 \% \mathrm{w} / \mathrm{v})$ and methamidophos were highly antagonistic ( $>73.7 \%$ of reduction) to $M$. anisopliae sporulation $(p<0.05)$. Since cypermethrin inhibited mycelial growth, no conidial production was observed in this treatment (Figure 1).

According to the Biological Index, methyl parathion, thiamethoxam and lambda-cyhalothrin were compatible with $M$. anisopliae CG 168, while fipronil $(20 \% \mathrm{w} / \mathrm{v})$, fipronil $(25 \% \mathrm{w} / \mathrm{v})$, thiamethoxam + lambda-cyhalothrin and methamidophos were classified as moderately toxic (Table 2). Among the insecticides tested only cypermethrin was not compatible with $M$. anisopliae. 

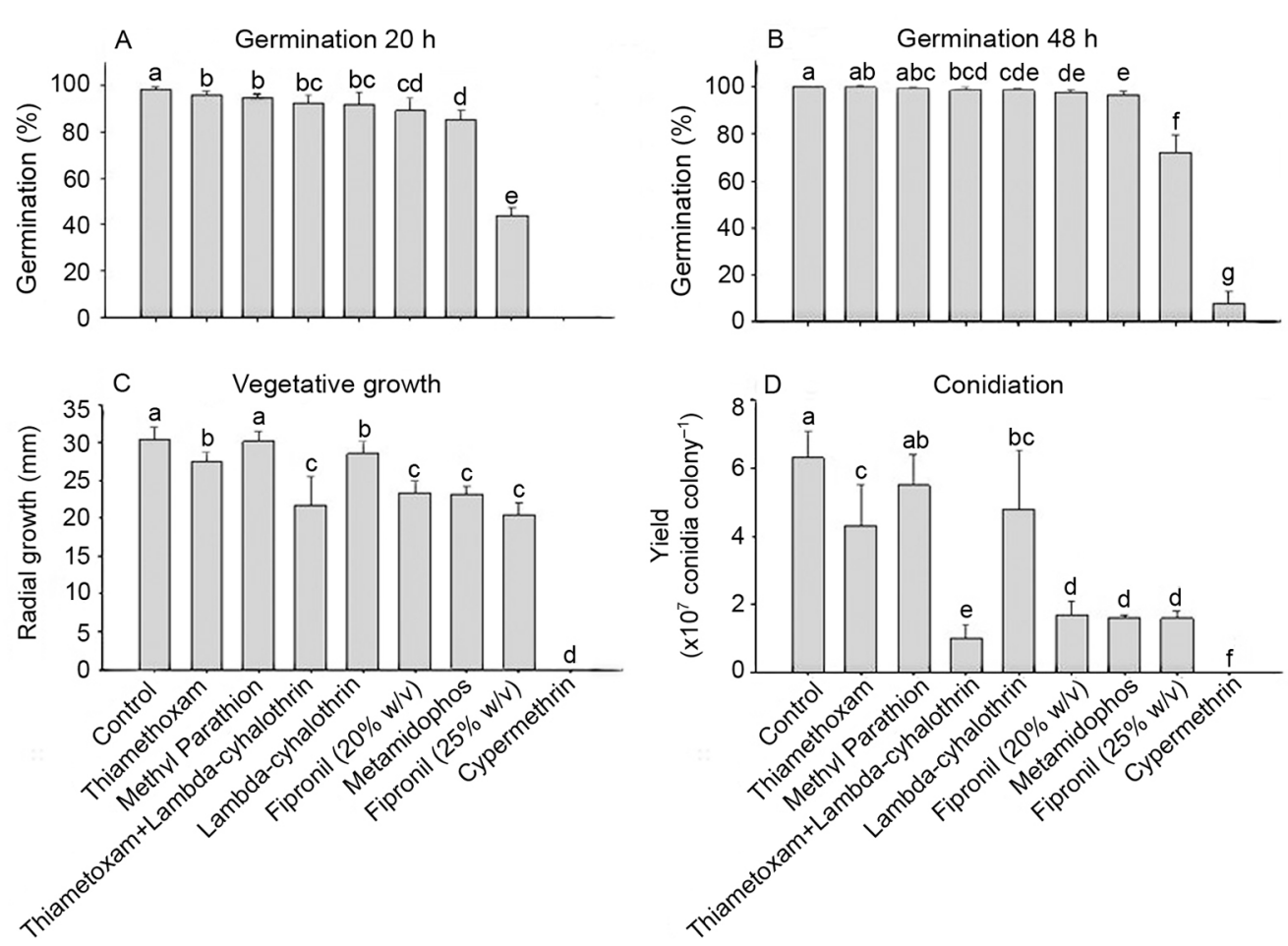

Figure 1 - Effect of insecticides on biological parameters of Metarhizium anisopliae CG 168 at $25{ }^{\circ} \mathrm{C}$ and $12 \mathrm{~h}$ photophase. Means follwed by the same letters are not significantly different by Fisher's LSD test $(p \leq 0.05)$. Number of replicates per treatment was $6-8$. Only distilled water plus Tween 80 (0.01\%) was used in the control group.

Table 2 - Toxicological classification of registered agrochemicals for rice production toward Metarhizium anisopliae strain CG 168 based on the Biological Index formula proposed by Rossi-Zalaf et al. (2008).

\begin{tabular}{lcc}
\hline Agrochemical & Biological Index & Classification \\
\hline Insecticide & & \\
\hline Standak & 47.2 & Moderately toxic \\
Bravik & 94.0 & Compatible \\
Actara & 81.8 & Compatible \\
Engeo Pleno & 49.9 & Moderately toxic \\
Karate Zeon & 86.3 & Compatible \\
Klap & 56.8 & Moderately toxic \\
Tamaron & 55.6 & Moderately toxic \\
Nor-trin & 0.0 & Toxic \\
\hline Herbicide & & \\
\hline Roundup & 80.5 & Compatible \\
DMA & 0.0 & Toxic \\
Basagran & 78.4 & Compatible \\
Kifix & 83.2 & Compatible \\
Herbadox & 43.6 & Moderately toxic \\
\hline Fungicide & & \\
\hline Score & 65.0 & Moderately toxic \\
Flint & 46.5 & Moderately toxic \\
Stratego & 60.9 & Moderately toxic \\
Priorib & 72.6 & Compatible \\
\hline aFor computation of the Biological Index, conidial germination at 20 h was used. \\
bAlthough azoxystrobin was scored as selective to M.anisopliae according to \\
the Biological Index formula, we recommend that it not be used in combination \\
with the fungus, as it prevented conidial germination at 20 h.
\end{tabular}

All herbicides inhibited germination at $20 \mathrm{~h}$ and no germination was observed when $M$. anisopliae conidia were exposed to pendimethalin and 2,4-Dichlorophenoxyacetic acid $(2,4-\mathrm{D})(F=255.22 ; d f=5,29 ; p<$ 0.0001 ) (Figure 2). After $48 \mathrm{~h}$, the germination rate of the treatments with imazapic + imazapyr and bentazon were similar to the control $(p>0.05)$, whereas the other herbicides considerably reduced the conidial germination $(F$ $=715.18 ; d f=5,29 ; p<0.0001$ ) (Figure 2). In addition, glyphosate delayed conidial germination with only $8.2 \%$ germination at $20 \mathrm{~h}$ but $96.4 \%$ at $48 \mathrm{~h}$.

Most herbicides reduced mycelial growth in comparison with the control $\left(\chi^{2}=39.47 ; d f=5 ; p<0.0001\right)$, except for glyphosate $(p>0.05)$. A complete suppression of vegetative growth of $M$. anisopliae was caused by $2,4-\mathrm{D}$, and consequently no conidia were produced (Figure 2). All herbicides had a deleterious effect on conidial yield compared to the control $\left(\chi^{2}=36.53 ; d f\right.$ $=5 ; p<0.0001)$, with pendimethalin and 2,4-D causing the highest reduction in fungal conidiation $181.8 \%$ and $100 \%$, respectively). According to the Biological Index, glyphosate, bentazon and imazapic + imazapyr were compatible with $M$. anisopliae CG 168, while pendimethalin was classified as moderately toxic and 2,4-D toxic (Table 2).

Similar to other chemical groups, all fungicides negatively affected $M$. anisopliae germination at $20 \mathrm{~h}(F=$ 1246.20; $d f=4,20 ; p<0.0001)$ and $48 \mathrm{~h}(F=256.62 ; d f$ 

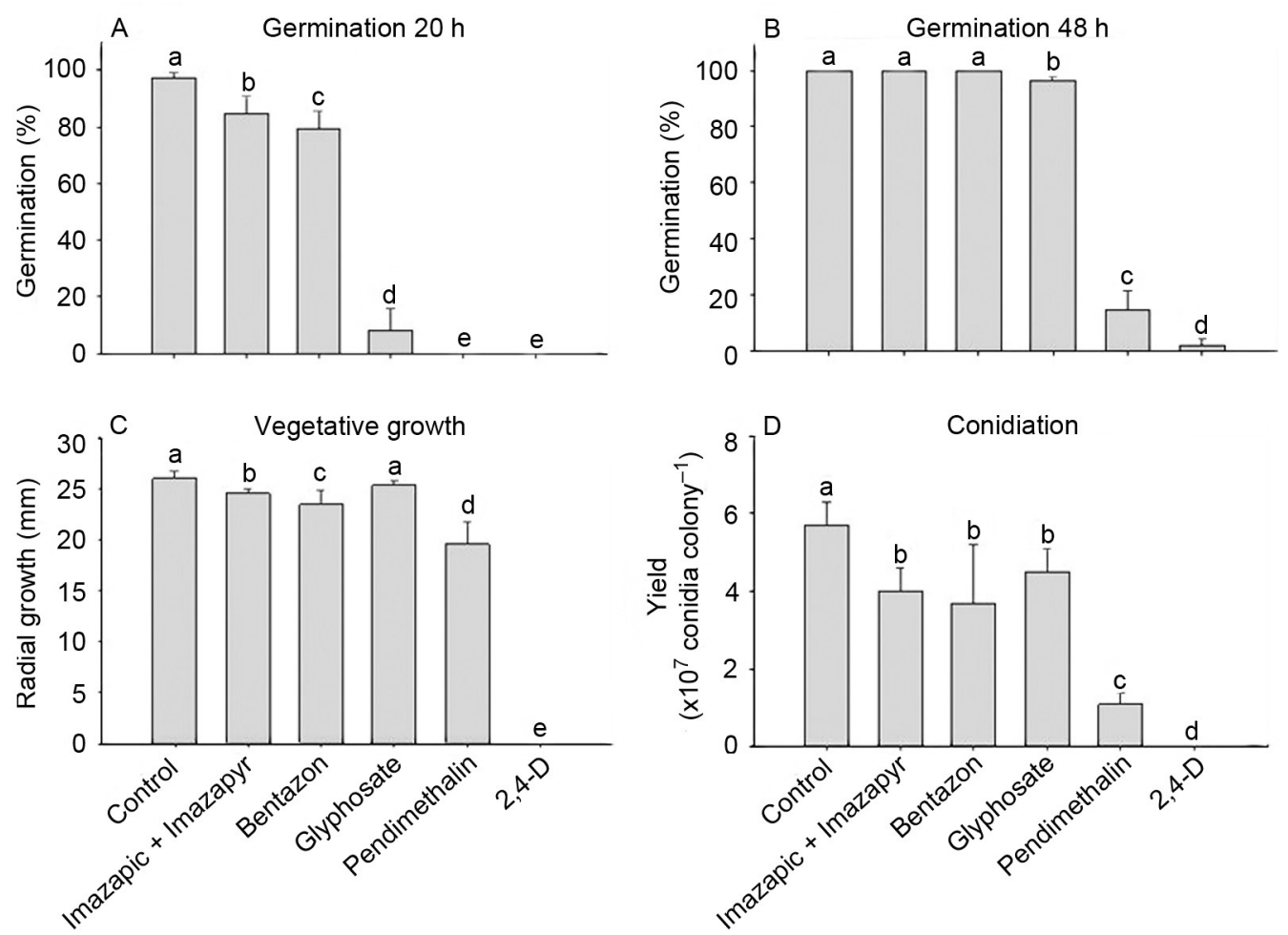

Figure 2 - Effect of herbicides on biological parameters of Metarhizium anisopliae CG 168 at $25^{\circ} \mathrm{C}$ and $12 \mathrm{~h}$ photophase. Means follwed by the same letters are not significantly different by Fisher's LSD test $(p \leq 0.05)$. Number of replicates per treatment was $6-8$. Only distilled water plus Tween 80 (0.01\%) was used in the control group.

$=4,20 ; p<0.0001$ ) compared to the controls (Figure 3). Trifloxystrobin and azoxystrobin were the most deleterious fungicides for fungal germination at $20 \mathrm{~h}$, since no germinated conidia were observed. However, some germination occurred after $48 \mathrm{~h}$ incubation (48-52 \%) indicating that trifloxystrobin and azoxystrobin delayed conidial germination. Vegetative growth and conidial yield were inhibited by all fungicides $(F=54.4 ; d f=4,32 ; p<0.0001$; $F=107.51 ; d f=4,32 ; p<0.0001$, respectively $)$. Difenoconazole, propiconazole and trifloxystrobin caused more than $50 \%$ of reduction of $M$. anisopliae conidiation. According to the Biological Index, azoxystrobin was the only compatible fungicide with $M$. anisopliae CG 168, whereas difenoconazole, propiconazole and trifloxystrobin were classified as moderately toxic (Table 2). No fungicide was scored as toxic to this fungus.

For the analysis of the chemical groups through a comparison of pooled means, it was shown that all tested products reduced the biological parameters of $M$. anisopliae CG 168 to some extent. Insecticides comprised the least deleterious products to $M$. anisopliae. Fungicides and herbicides inhibited in a higher degree the mycelial growth of $M$. anisopliae than insecticides $\left(\chi^{2}\right.$ $=36.97 ; d f=3 ; p<0.0001)$, whereas all pesticides considerably reduced the conidial production compared to the control $\left(\chi^{2}=33.06 ; d f=3 ; p<0.0001\right)$ at the same extent. Fungicides inflicted the most harmful effect on germination at $20 \mathrm{~h}\left(\chi^{2}=64.28 ; d f=3 ; p<0.0001\right)$ and $48 \mathrm{~h}$ incubation $\left(\chi^{2}=33.31 ; d f=3 ; p<0.0001\right)$. Moreover, although herbicides reduced the germination at 20 $\mathrm{h}$ in comparison to insecticides, there was no difference among chemical groups after $48 \mathrm{~h}$.

\section{Discussion}

None of the tested agrochemicals at label rate recommendations promoted positive effects on developmental stages of $M$. anisopliae. It is possible that those products compatible with $M$. anisopliae, especially the insecticides, might be used at sublethal dosages in combination with the fungus in further studies aimed at improving its virulence against T. limbativentris or even to broaden its host range in rice crops.

Although the insecticides methamidophos, methyl parathion, thiamethoxam + lambda-cyhalothrin, Kara$\mathrm{te}^{\mathrm{TM}}$, fipronil $(20 \% \mathrm{w} / \mathrm{v})$, thiamethoxam and the herbicide imazapic + imazapyr differed from the control, conidial germination in these treatments was high, ranging from 84.6 to $95.8 \%$. These levels of germination suggest that these insecticides would be suitable for using in combination with $M$. anisopliae for insect control as part of an integrated pest management strategy. 

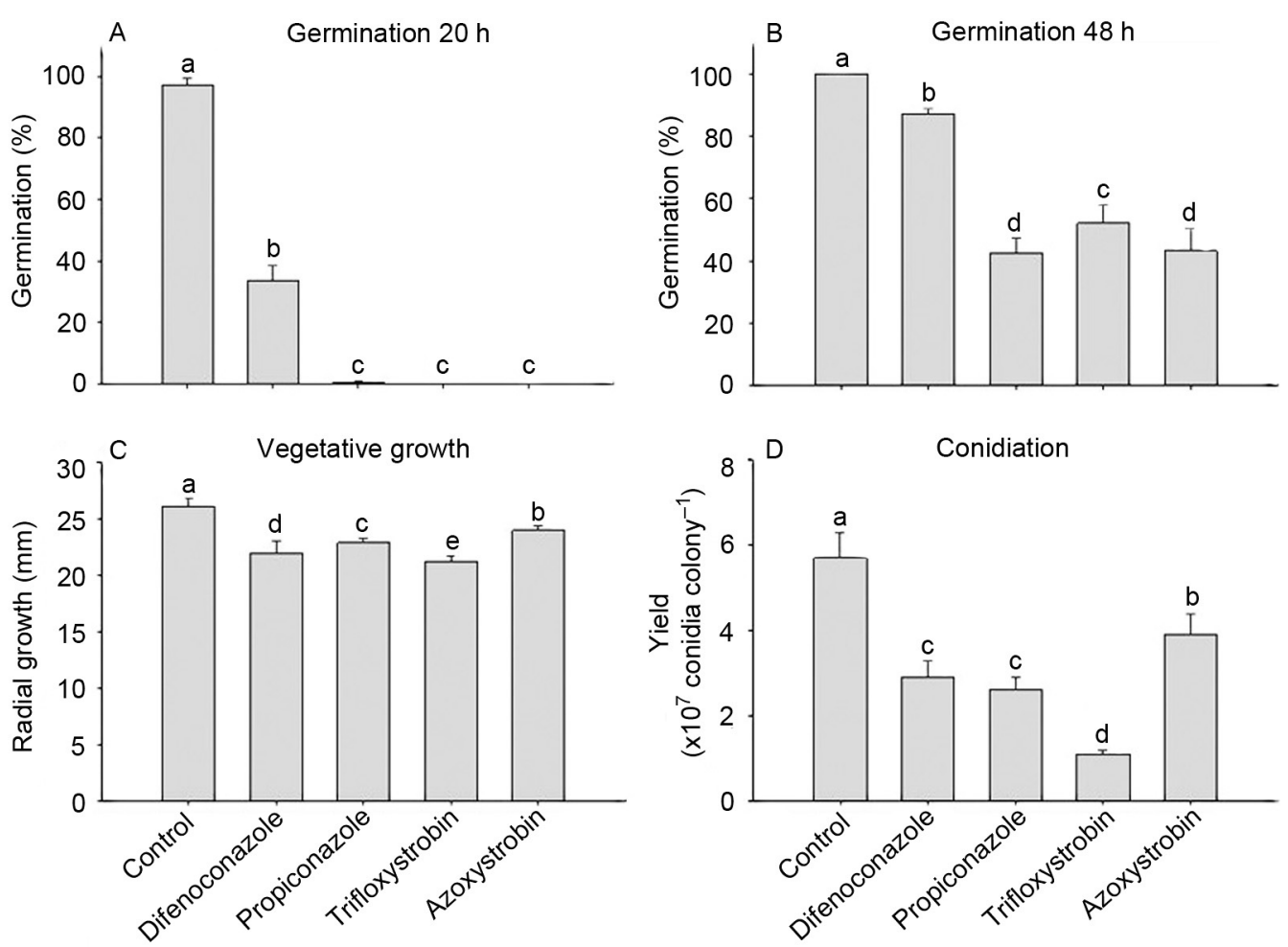

Figure 3 - Effect of fungicides on biological parameters of Metarhizium anisopliae CG 168 at $25^{\circ} \mathrm{C}$ and $12 \mathrm{~h}$ photophase. Means follwed by the same letters are not significantly different by Fisher's LSD test $(p \leq 0.05)$. Number of replicates per treatment was $6-8$. Only distilled water plus Tween 80 (0.01\%) was used in the control group.

Some of the agrochemicals tested delayed conidial germination of $M$. anisopliae as seen in the increased germination from 20 to $48 \mathrm{~h}$ incubation. As example, Fipronil (25\% w/v), glyphosate, difenoconazole, propiconazole, trifloxystrobin and azoxystrobin had fungistatic activity on conidial germination at $20 \mathrm{~h}$; however by $48 \mathrm{~h}$ germination of the fungus was still occurring after mixing it with these products. The fungicide azoxystrobin inhibited conidial germination at $20 \mathrm{~h}$ but allowed larger mycelial growth and greater conidiation compared to the other fungicides, and thus was classified as compatible according to the Biological Index formula. The effect of these products on conidial germination was probably due to the active ingredient and/or to some components of the inert carriers in the formulation. Quintela and McCoy (1998) observed that one component of the inert carrier of the insecticide Admire ${ }^{\mathrm{TM}} 2 \mathrm{~F}$ (Bayer Corporation) affected conidial germination of $M$. anisopliae. The fungicidal activity of the chemical group strobilurins (azoxystrobin and trifloxystrobin) relies on the ability of the active ingredient to disrupt energy production in fungal mitochondria and consequently prevents spore germination. In the triazole fungicides (difenoconazole and propiconazole), ergosterol biosynthesis is inhibited; consequently preventing fungal cell membranes formation (Bartlett et al., 2002). Our results are in agreement with the mode of action of the strobilurins azoxystrobin and trifloxystrobin as they negatively affected conidial germination at 20 and $48 \mathrm{~h}$, meanwhile the triazoles difenoconazole and propiconazole reduced conidial germination, mycelial growth and conidiation.

Herbicide 2,4-D and the insecticide cypermethrin were the most harmful to $M$. anisopliae CG 168 as they completely inhibited conidial germination, vegetative growth and conidiation. The compound 2,4-D acts by inhibiting the enzyme acetyl-CoA carboxylase, and as a result, prevents the biosynthesis of fatty acids and glucosylceramides, which are components of membrane lipids of animals, plants, and fungi (Leipelt et al., 2001). It remains unclear how the insecticide cypermethrin or other cypermethrin-based insecticides act on fungi. In contrast to the results obtained in the present study, Rachappa et al. (2007) pointed out that pyrethroids were safer to the developmental stages of $M$. anisopliae, but this interaction depends on methodological procedures, pesticide formulations and fungal strains. The compatibility of $M$. anisopliae with thiamethoxam and lambdacyhalothrin is in agreement with other studies (Batista Filho et al., 2001; Cavalcanti et al., 2002; Loureiro et al., 2002; Neves et al., 2001; Rampelotti-Ferreira et al., 2010). Despite the insecticide thiamethoxam + lambdacyhalothrin is a combination of two compatible insec- 
ticides, it was scored as moderately toxic in this study. The combination of two or more active ingredients in an agrochemical may reduce or increase the degree of compatibility via synergism or antagonism (Alves, 1998). In the present study, none of the agrochemicals tested were synergistic to $M$. anisopliae.

At doses of 160 and $240 \mathrm{~mL} \mathrm{ha}{ }^{-1}$ the insecticide fipronil $(25 \% \mathrm{w} / \mathrm{v})$ was not detrimental to $M$. anisopliae mycelial growth and conidiation; therefore, it was scored as compatible (Rampelotti-Ferreira et al., 2010). However, in our study, this product was classified as moderately toxic to $M$. anisopliae CG 168 when using the same Biological Index. These results cannot be compared because the experimental methodology and fungal isolates were different. These authors as well as Schumacher and Poehling (2012) incorporated the test pesticides into PDA medium. Conversely, in our study the pesticides were added to an aqueous suspension of conidia for three hours of exposure under constant agitation in a rotary shaker. We provided a novel and more reliable compatibility method based on a tank mixing with fungal conidia and agrochemicals for an integrated application approach, enabling conidia to be totally exposed to the chemical product for a certain period of time, and thus can be considered a more realistic method than the other in which the pesticide is incorporated into the solid medium. The precipitation of some chemicals, especially those in granular and wettable powder formulations, cannot be avoided with the previous method (solid medium). Therefore, these pesticides may not have an even dilution in the solid medium due to differences in density, which would compromise the direct contact between the chemical and conidia (Silva et al., 2005).

According to the Biological Index, the fungicide azoxystrobin was classified as compatible with $M$. anisopliae, enabling normal vegetative growth and sporulation, although there were no germinated conidia after $20 \mathrm{~h}$ of incubation. This result seems anomalous, because a compatible pesticide should not affect conidial germination. Any chemical pesticide preventing conidial germination up to $20 \mathrm{~h}$ should not be used in combination with this fungus, since the conidial germination is the first step to initiate the fungal infection process in the insect. If conidial germination is delayed or inhibited, the potential for the fungus to infect insects in the field will be greatly reduced. In the field, fungal conidia must cope with abiotic and biotic factors detrimental to survival and most of conidial survival on the leaves is lost after $24 \mathrm{~h}$ because of environmental constraints such as solar radiation, high temperature, low relative humidity, rainfastness, and plant allelochemicals (Jaronski, 2010). In addition, the high and fast germination rate for fungal entomopathogens has a positive relationship with their virulence toward a host (Altre et al., 1999; Hassan et al., 1989; Rangel et al., 2008). Faster conidial germination indicates non-stressed conidia which play an important role for the success of biological control of insects and should be the major concern in quality control protocols for conidia-based mycoinsecticides (Faria et al., 2010). Faria et al. (2010) assumed that only vigorous conidia of Beauveria and Metarhizium which germinated quickly within $24 \mathrm{~h}$ incubation should be considered suitable for insect control. On the other hand, conidia germinating after $24 \mathrm{~h}$ should be considered debilitated spores (low vigor), as they may cause low insect mortalities and thus should not be used for insect control. As a result, the outcome from conidia that germinated at $20 \mathrm{~h}$ instead of at $48 \mathrm{~h}$ to calculate the Biological Index was used (Table 2), since those vigorous and non-stressed conidia are able to germinate faster and thus are much more likely to have success in germinating and penetrating through the insect cuticle and escape from environmental stresses.

The fact that insecticides, fungicides and herbicides inhibit mycelial growth of a fungal entomopathogen is not necessarily indicative of reduction in sporulation and conidial germination and vice versa (Zimmermann, 1975). Some agrochemicals can delay mycelial growth, although they can stimulate higher conidiation later, presumably in response to stresses caused by the chemical product, perhaps due to the reduced early mycelial growth. In other cases, the fungus grows well during its vegetative development, but later conidiation does not take place for reasons which are not understood. There is no positive relationship between vegetative growth and conidial yield and the factors that govern this outcome warrant further detailed investigations (Tamai et al., 2002). In the current Biological Index proposed by Rossi-Zalaf et al. (2008), there is a low weight attributed to the germination parameter (i.e., $10 \%$ ) in comparison to the other variables /vegetative growth and conidiation). As a result, the Biological Index may in some cases mask the real toxic impact of an agrochemical on entomopathogenic fungi, since $90 \%$ of the formula is attributed to vegetative growth and sporulation.

Conidial germination is more important than vegetative growth and sporulation on cadavers, because the former corresponds to the first step that triggers an epizootic, and the fungus relies on it to infect the host successfully (Alizadeh et al., 2007; Khalil et al., 1985). Thereby, if an agrochemical causes substantial decrease in conidial germination, it may reduce the effectiveness of the entomopathogen toward its target. As mycelial growth develops inside the insect host and the concentration of agrochemicals, especially those with systemic mode of action, are usually found in low titer in the hemolymph, there is little chance of this developmental stage to be negatively affected (Khalil et al., 1985). On the other hand, vegetative growth and conidiation are also important in regards to secondary infections caused by fungi and thus they should be considered for fungal virulence and persistence in the environment (Schumacher and Poehling, 2012). The current Biological Index for toxicological classification of pesticides has merit regarding the ability of a fungus to grow saprophytically in the environment and to produce secondary inoculum sources through sporulation on cadavers. Such factors 
are related to the conservational approach for entomopathogens in agroecosystems. Based on all the facts mentioned above, we have identified a situation where this formula is not reliable since it produced a classification of compatible for an agrochemical that reduced conidial germination. Therefore, we strongly contend that the formula of Biological Index proposed by Rossi-Zalaf et al. (2008) must be revised carefully by researchers giving special attention to improving the incorporation of information regarding conidial germination.

For successful control of T. limbativentris in rice crops adopting integrated pest management, the awareness of such compatible agrochemicals is very useful to ensure safety fungal application and to facilitate the combination of the fungus with chemical products. On the other hand, for those chemicals not compatible with the fungus, there are two strategies which might be employed to prevent $M$. anisopliae from harmful exposures: i) plan fungus application for two to four days before the chemical spraying (the exact time depends on the residual effect of each product), so that the fungus would have enough time to infect the host (Kouassi et al., 2003); and ii) use of a conidial formulation in oil to reduce the fungistatic effect of pesticides on fungal performance. Recently, Lopes at al. (2011) showed that an oil-based formulation afforded protection to aerial conidia of $M$. anisopliae against products with fungistatic or fungicide activity and this formulation also enhanced fungal virulence on Diatraea saccharalis (Lepidoptera: Crambidae) larvae. In addition, there may be some compatible insecticides which can be used at low label rates in combination with the fungus aiming to lower the insect immunity and consequently increase fungal effectiveness.

In summary, our findings from in vitro compatibility indicate that the tested fungicides are more detrimental to conidial germination, mycelial growth and sporulation of $M$. anisopliae CG 168 than herbicides and insecticides, and they should not be applied together with this fungus in tank mixing. The agrochemicals compatible with $M$. anisopliae CG 168 are: insecticides methyl parathion (240 $\left.\mathrm{mL} \mathrm{ha}^{-1}\right)$, thiamethoxam (31 $\left.\mathrm{g} \mathrm{ha}^{-1}\right)$, and lambda-cyhalothrin $\left(6.3 \mathrm{~mL} \mathrm{ha}^{-1}\right)$; herbicides glyphosate (1560 $\left.\mathrm{mL} \mathrm{ha}^{-1}\right)$, bentazon (720 $\left.\mathrm{mL} \mathrm{ha}{ }^{-1}\right)$, and imazapic + imazapyr (84 $\left.\mathrm{g} \mathrm{ha}^{-1}\right)$. Although the results of our in vitro study did not consider the effect of many variables associated with field use of pesticides, our findings are of paramount importance to guide and advice farmers to use safely this entomopathogen in combination with pesticides registered for rice crops without affecting fungal virulence and germination.

\section{Acknowledgments}

We are very grateful to Dr. Anne Sitarama Prabhu and Ana Lúcia Delalibera de Faria for their assistance with the revision of this paper. This work was supported by Empresa Brasileira de Pesquisa Agropecuária (Embra-
pa/Brasília/Brazil) and by National Council for Scientific and Technological Development (CNPq-REPENSA, project number 562621/2010-5).

\section{References}

Alizadeh, A.; Samih M.A.; Khezri, M.; Riseh, R.R. 2007. Compatibility of Beauveria bassiana (Bals.) Vuill. with several pesticides. International Journal of Agriculture and Biology 9: 31-34.

Altre, J.A.; Vandenberg, J.D.; Cantone, F.A. 1999. Pathogenicity of Paecilomyces fumosoroseus isolates to diamondback Moth, Plutella xylostella: correlation with spore size, germination speed, and attachment to cuticle. Journal of Invertebrate. Pathology 73: 332-338.

Alves, S.B. 1998. Fungos entomopatogênicos = Entomopathogenic fungi. p. 289-381. In: Alves, S.B., ed. Controle microbiano de insetos $=$ Microbial control of insects. Fealq, Piracicaba, SP, Brazil.

Alves, S.B.; Lecuona, R.E. 1998. Epizootiologia aplicada ao controle microbiano $=$ Applied epizootiology to microbial control. p. 97-157. In: Alves, S.B., ed. Controle microbiano de insetos $=$ Microbial control of insects. Fealq, Piracicaba, SP, Brazil.

Alves, S.B.; Moino Jr., A.; Almeida, J.E.M. 1998. Produtos fitossanitários e entomopatógenos $=$ Phytosanitary products and entomopathogens. p. 649-672. In: Alves, S.B., ed. Controle microbiano de insetos $=$ Microbial control of insects. Fealq, Piracicaba, SP, Brazil.

Bartlett, D.W.; Clough, J.M.; Godwin, J.R.; Hall, A.A.; Hamer, M.; Parr-Dobrzanski, B. 2002. The strobilurin fungicides. Pest Management Science 58: 649-662.

Batista Filho, A.; Almeida, J.E.M.; Lamas, C. 2001. Effect of Thiamethoxan on entomopathogenic microorganisms. Neotropical Entomology 30: 437-447.

Bischoff, J.F.; Rehner, S.A.; Humber, R.A. 2009. A multilocus phylogeny of the Metarhizium anisopliae lineage. Mycologia 101: 508-528.

Brasil. Ministério da Agricultura [MAPA]. 2009. AGROFIT Sistema de Agrotóxicos Fitossanitários = AGROFIT Phytosanitary Pesticides System. Available at: http://www.agricultura.gov. br/portal/page/portal/Internet-MAPA/pagina-inicial/servicos-esistemas/sistemas/agrofit [Accessed May 23, 2009].

Cavalcanti, R.S.; Moino Jr, A.; Souza, G.C.; Arnosti, A. 2002. Evaluation of the effect of pesticides on the development of the fungus Beauveria bassiana (bals.) vuill. Arquivos do Instituto Biológico 69: 17-22 (in Portuguese, with abstract in English).

Faria, M.; Hotchkiss, J.H.; Hajek, A.E.; Wraight, S.P. 2010. Debilitation in conidia of the entomopathogenic fungi Beauveria bassiana and Metarhizium anisopliae and implication with respect to viability determinations and mycopesticide quality assessments. Journal of Invertebrate Pathology 105: 74-83.

Ferreira, E.; Martins, J.F.S.; Rangel, P.H.N.; Cutrim, V.A. 1986. Resistência de arroz ao percevejo-do-colmo $=$ Rice resistance to the rice stink bug. Pesquisa Agropecuária Brasileira 21: 565-569.

Hassan, A.E.M.; Dillon, R.J.; Charnley, A.K. 1989. Influence of accelerated germination of Conidia on the pathogenicity of Metarhizium anisopliae for Manduca sexta. Journal of Invertebrate Pathology 54: 277-279. 
Hu, G.; St. Leger, R.J. 2002. Field studies using a recombinant mycoinsecticide (Metarhizium anisopliae) reveal that it is rhizosphere competent. Applied and Environmental Microbiology 68: 6383-6387.

Jaronski, S.T. 2010. Ecological factors in the inundative use of fungal entomopathogens. BioControl 55: 159-185.

Khalil, S.K.; Shah, M.A.; Naeem, M. 1985. Laboratory studies on the compatibility of the entomopathogenic fungus Verticillium lecanii with certain pesticides. Agriculture Ecosystems and Environment 13: 329-334.

Kouassi, M.; Coderre, D.; Todorova, S.I. 2003. Effects of the timing of applications on the incompatibility of three fungicides and one isolate of the entomopathogenic fungus Beauveria bassiana (Balsamo) Vuillemin (Deuteromycotina). Journal of Applied Entomology 127: 421-426.

Leipelt, M.; Warnecke, D.; Zähringer, U.; Ott, C.; Müller, F.; Hube, B.; Heinz, E. 2001. Glucosylceramide synthases, a gene family responsible for the biosynthesis of glucosphingolipids in animals, plants and fungi. Journal of Biological Chemistry 276: 33621-33629.

Lopes, R.B.; Pauli, G.; Mascarin, G.M.; Faria, M. 2011. Protection of fungal conidia afforded by an oil-based formulation against non-compatible fungicides. Biocontrol Science and Technology 21: $125-137$.

Loureiro, E.S.; Moino Jr, A.; Arnosti, A.; Souza, G.C. 2002. Effect of chemical products used in lettuce and chrysanthemum on entomopathogenic fungi. Neotropical Entomology 31: 263-269 (in Portuguese, with abstract in English).

Luz, C.; Fargues, J. 1997. Temperature and moisture requirements for conidial germination of an isolate of Beauveria bassiana, pathogenic to Rhodnius prolixus. Mycopathologia 138: 117125.

Martins, J.F.S.; Botton, M.; Carbonari, J.J.; Quintela, E.D. 2004. Efficiency of Metarhizium anisopliae on rice stem bug Tibraca limbativentris (Heteroptera: Pentatomidae) control in flooded rice Field. Ciência Rural 34: 1681-1688 (in Portuguese, with abstract in English).

Neves, P.M.O.J.; Hirose, E.; Tchujo, P.T.; Moino Jr., A. 2001. Compatibility of entomopathogenic fungi with neonicotinoids insecticides. Neotropical Entomology 30: 263-268.

Quintela, E.D.; McCoy, C.W. 1997. Pathogenicity enhancement of Metarhizium anisopliae and Beauveria bassiana to first instar of Diaprepes abbreviatus (Coleoptera: Curculionidae) with sublethal doses of imidacloprid. Environmental Entomology 26: $1173-1182$.

Quintela, E.D.; McCoy, C.W. 1998. Conidial attachment of Metarhizium anisopliae and Beauveria bassiana to the larval cuticle of Diaprepes abbreviatus (Coleoptera: Curculionidae) treated with imidacloprid. Journal of Invertebrate Pathology 72: 220-230.

Rachappa, V.; Lingappa, S.; Patil, R.K. 2007. Effect of agrochemicals on growth and sporulation of Metarhizium anisopliae (Metschnikoff) sorokin. Karnataka Journal of Agricultural Sciences 20: 410-413.
Rampelotti, F.T.; Ferreira, A.; Prando, H.F.; Grützmacher, A.D.; Martins, J.F.S.; Tcacenco, F.A.; Mattos, M.L.T. 2007. Patogenicity of Metarhizium anisopliae (metsch.) sorokin on the phases of the development of Tibraca limbativentris stal (hemiptera: pentatomidae) under laboratory conditions. Arquivos do Instituto Biológico 74: 141-148 (in Portuguese, with abstract in English).

Rampelotti-Ferreira, F.T.; Ferreira, A.; Prando, H.F.; Tcacenco, F.A.; Grützmacher, A.D.; Martins, J.F.S. 2010. Selectivity of chemical pesticides used in rice irrigated crop at fungus Metarhizium anisopliae, microbial control agent of Tibraca limbativentris. Ciência Rural 40: 745-751 (in Portuguese, with abstract in English).

Rangel, D.E.N.; Alston, D.G.; Roberts, D.W. 2008. Effects of physical and nutritional stress conditions during mycelial growth on conidial germination speed, adhesion to host cuticle, and virulence of Metarhizium anisopliae, an entomopathogenic fungus. Mycological Research 112: 1355-1361.

Rossi-Zalaf, L.S.; Alves, S.B.; Lopes, R.B.; Silveira Neto, S.; Tanzini, M.R. 2008. Interação de microorganismo com outros agentes de controle de pragas e doenças = Microorganism interaction with other pest and disease control agents. p. 279302. In: Alves, S.B. and Lopes, R.B., eds. Controle microbiano de pragas na América Latina: avanços e desafios = Microbial control of pest in Latin America: advances and challenges. Fealq, Piracicaba, SP, Brazil.

SAS Institute. 2008. SAS/STAT ${ }^{\circledR}$, Release 9.2: User's Guide. Cary, NC, USA.

Schumacher, V.; Poehling, H.M. 2012. In vitro effect of pesticides on the germination, vegetative growth, and conidial production of two strains of Metarhizium anisopliae. Fungal Biology 116: 121-132.

Silva, R.Z.; Neves, P.M.O.J.; Santoro, P.H. 2005. Techniques and parameters used in compatibility studies between entomopathogenic fungi and phytosanitary products. Ciências Agrárias 26: 305-312 (in Portuguese, with abstract in English).

Tamai, M.A.; Alves, S.B.; Lopes, R.B.; Faion, M.; Padulla, L.F.L. 2002. Toxicity of pesticides against Beauveria bassiana (Bals.) Vuill. Arquivos do Instituto Biológico 69: 89-96 (in Portuguese, with abstract in English).

Tanzini, M.R.; Alves, S.B.; Setten, A. 2002. Toxicity of phytossanitary products used for the control of Leptopharsa heveae to entomopathogenic fungi. Arquivos do Instituto Biológico 69: 65-69 (in Portuguese, with abstract in English).

Zimmermann, G. 1975. Über die wirkung systemischer fungizide auf verschiedene insektenoathogene fungi imperfecti in vitro $=$ Effect of systemic fungicides on different imperfect entomopathogenic fungi in vitro. Nachrichtenblatt des Deutschen Pflanzenschutzdienstes 27: 113-117 (in Germany, with abstract in English). 